\title{
Critical Aspects on the Control in the Low Temperature Combustion Systems for High Performance DI Diesel Engines
}

\author{
C. Beatrice", G. Avolio, C. Bertoli, N. Del Giacomo, C. Guido and M.na Migliaccio \\ Istituto Motori - Consiglio Nazionale delle Ricerche, Viale Marconi 8, 80125 Napoli - Italy \\ e-mail: c.beatrice@im.cnr.it - g.avolio@im.cnr.it - c.bertoli@im.cnr.it - n.delgiacomo@im.cnr.it - c.guido@im.cnr.it - m.migliaccio@im.cnr.it \\ * Scientific Correspondent
}

\begin{abstract}
Résumé - Aspects critiques du contrôle des systèmes de combustion de type Low Temperature pour moteurs DI Diesel High Performance - Cette publication présente une approche pour le contrôle de la combustion à basse température (Low Temperature Combustion : LTC), actuellement en développement pour les applications sur moteurs Diesel, avec une description et une analyse de certains des aspects critiques inhérents à ce type de motorisation. Une comparaison des émissions en combustion LTC et conventionnelle obtenue sur un moteur 4 cylindres Diesel haute performance est d'abord présentée. Elle met en évidence les difficultés rencontrées dans la zone de fonctionnement faible régime-faible charge. Cette sensibilité est en particulier due à la gestion délicate de l'alimentation cylindre à cylindre en air et en carburant. Les aspects critiques du contrôle pendant les transitions de mode de combustion comme l'apparition du bruit, la chute de puissance ou les pics d'émissions de fumée favorisés par les différences des temps de réponse des composants de la boucle d'air, de la boucle EGR et du système d'injection sont ensuite présentés. Finalement, les principales voies de recherche pour améliorer le contrôle des applications LTC sont décrites.
\end{abstract}

\footnotetext{
Abstract - Critical Aspects on the Control in the Low Temperature Combustion Systems for High Performance DI Diesel Engines - The present paper describes one of the Low Temperature Combustion (LTC) management philosophies, today under development for application to Diesel engines, showing and analysing some critical aspects deriving from its use. In particular, starting from the analysis of the application of LTC to a four-cylinder Diesel engine, at the state of the art of current technology, the emission performance for LTC and conventional Diesel combustion are compared, together with the constraint in the application of LTC to the limited low load-low speed range. Moreover, the problems relative to different airlfuel feeding for each cylinder, knocking, torque drop and high smoking event during transient conditions, different actuation velocity of the components (of injection, turbo, EGR and swirl control systems) during the switch between LTC and conventional combustion, are presented and critically commented, indicating the main research drivelines for practical application.
} 


\section{DEFINITIONS, ACRONYMS, ABBREVIATIONS}

$\begin{array}{ll}\text { LTC } & \text { Low Temperature Combustion } \\ \text { UNIBUS } & \text { Uniform Bulky Combustion System } \\ \text { PCCI } & \text { Premixed Charge Compression Ignition } \\ \text { MK } & \text { Modulate Kinetic Combustion } \\ \text { MBF50\% } & 50 \% \text { of Burned Fuel Mass } \\ \text { TDC } & \text { Top Dead Center } \\ \text { BMEP } & \text { Brake Mean Effective Pressure } \\ \text { BSFC } & \text { Brake Specific Fuel Consumption } \\ \text { NEDC } & \text { New European Driving Cycle } \\ \text { IMEP } & \text { Indicated Mean Effective Pressure } \\ \text { VVA } & \text { Variable Valve Actuation Systems }\end{array}$

\section{INTRODUCTION}

In the last ten years, all most world important research centres have progressively increased their effort in the "low-temperature" combustion concept development (LTC) in order to follow the more and more stringent emissions EU target. In this way, relatively to Diesel engines, different combustion system managements were developed, each one named with an acronym as pointed out from Duret [1]. For all systems, the flame temperature reduction is based on the realization of the adequate premixed air-fuel charge level and EGR level.

One of the main drawbacks in the practical application of the LTC systems is the limitation of their use in the low load and speed range of the whole engine operation map. In order to overcome this handicap, some systems are based on the deepen re-design of the combustion system architecture, while others are oriented to a better use of combustion management possibilities offered by modern technology, minimising changes in the architecture.

Generally, the first choice permits better performance under LTC operation mode, because the engine can be designed ad hoc to meet the wanted premixed conditions [2], but it can suffer in reaching the maximum power density of the modern engines for passenger cars.

On the other hand, the use of the well developed architecture of actual production engines, offers more difficulties in applying LTC concepts in a adequate engine map in order to meet the future post-EURO 5 emission limits, even if it preserves the standards in terms of maximum power-torque and fuel consumption performance.

For both choices a lot of combustion control problems must be overcome yet, both in steady-state and transient conditions. In particular, for the use of LTC in the production engine architecture, some drawbacks derive from the difficulties in the preparation of the optimum air-EGR-fuel premixed charge, the differences between the cylinders in terms of airEGR distribution, wall temperature, swirl, etc. and the differences in terms of actuation velocity of the engine components controlling the combustion (injection, air flow, turbocharged and EGR systems) during transient conditions.
Some of these drawbacks were experimentally analysed in a four-cylinder production engine on which one of the LTC philosophy was applied. In particular, in the following, the emission performance for LTC and conventional Diesel combustion are compared, showing the limits in reducing the application of LTC to low load-low speed range and some technological aspects that would be improved.

\section{EXPERIMENTAL APPARATUS}

The experimental activity was done on a four-cylinder DI Diesel engine for passenger car application, able to meet EURO4 emission limits. The main engine characteristics are listed in Table 1. The engine is installed on a dynamic test bench and is fully instrumented for indicated signal measurements. In particular, for each cylinder a piezo-quartz pressure transducer was placed.

TABLE 1

Engine main characteristics

\begin{tabular}{c|c}
\hline Fiat 1.9 JTD-E4 & $\begin{array}{c}\text { 4 Cylinder Diesel } \\
\text { DI 16 Valves }\end{array}$ \\
\hline $\begin{array}{c}\text { Bore } \times \text { stroke }(\mathrm{mm}) / \\
\text { Displacement }\left(\mathrm{cm}^{3}\right)\end{array}$ & $82 \times 90.4 / 1910$ \\
\hline Compression ratio & $16.5: 1$ \\
\hline Variable swirl ratio & $2 \div 4.5$ \\
\hline FIE / Nozzle & $\begin{array}{c}3^{\circ} \text { generation Common } \\
\text { Rail / Microsac }\end{array}$ \\
\hline Turbocharger & Garret GT 15 WGT \\
\hline Piston bowl & Two stage oxy-catalyst \\
\hline After-treatment & Cooled with engine \\
EGR & coolant fluid \\
\hline
\end{tabular}

The test bench is instrumented for the measurement of all thermodynamic parameters and regulated pollutant emissions.

\section{THE CONCEPT OF LOW TEMPERATURE COMBUSTION FOR PRODUCTION DIESEL COMBUSTION SYSTEMS}

Generally, exception for the UNIBUS concept developed by Toyota [3], all LTC systems under development for production engines are based on the use of two alternative concepts: an early single injection before the TDC, and/or a late injection, starting around TDC, exploiting the increase of ignition delay time after TDC. The first is generally named PCCI (premixed charge compression ignition) and was the first 
LTC concept studied for Diesel engines [4, 5]. It uses the long ignition delay time of the very early injection in order to prepare a well premixed air-EGR-fuel charge before the start of combustion. The second, developed mainly by Nissan Motor Company and named from its researchers MK (Modulate Kinetic) [6], adopts a late injection, starting around TDC. In this way this alternative concept exploits the in-cylinder gas temperature and pressure drop occurring after the TDC, in order to realize an ignition delay time adequate for the fuel premixing and so limiting the pressure gradient after the start of the combustion.

For both concepts, the reduction of flame temperature, and so NOx formation, is realized by the use of relatively high EGR levels. In the following the combustion mode of the two concepts will be briefly explained. In particular the application of the PCCI mode is limited at low load experimental conditions ( 2 bar of BMEP), as described in the paragraph 2.1. Difficulties in controlling autoignition and pressure gradient of a premixed charge are not yet overcome at higher load conditions. On the contrary the paragraph 2.2 shows the application of the MK concept limited at medium load (5 bar of BMEP). In lower load conditions, in fact, the retarded injection timing of MK concept would cause an excessive fuel consumption.

\subsection{PCCI Combustion Concept}

As said above, the PCCI concept is founded on the use of an early injection, able to prepare a premixed air-fuel charge before the combustion start. The long ignition delay time derives from the combined effects of the early injection and EGR level. In these conditions the fuel can burn with low flame temperature and low pressure gradient value and with a MBF50\% value closer to the TDC. Figure 1 shows typical cylinder pressure behavior of PCCI combustion in comparison with a pilot-main injection combustion mode The engine test point is $2000 \mathrm{rpm}$ at 2 bar of BMEP. In the same figure energizing current (E.C.) and heat release rate curves are reported.

The management of this combustion type is very simple at low load and low speed, in which conditions the ignition delay time is sufficient to prepare a premixed charge. In these conditions, BSFC, emissions and noise are at same level of the conventional combustion performance as shown in Figure 2.

The comparison demonstrates the good potential of PCCI concept in controlling both soot and NOx emissions. Soot is double than the emission value with conventional Diesel, but it must be taken into account that this engine test point has a very low load and so for both combustion modes the exhaust values were very low (about $0.05 \mathrm{FSN}$ ).

On the contrary, a very large amount of unburned gaseous compounds like $\mathrm{CO}$ and $\mathrm{HC}$ ( $\mathrm{HC}$ are not reported in Figure 2 for brevity) are produced in the PCCI combustion mode with respect to the Diesel mode.

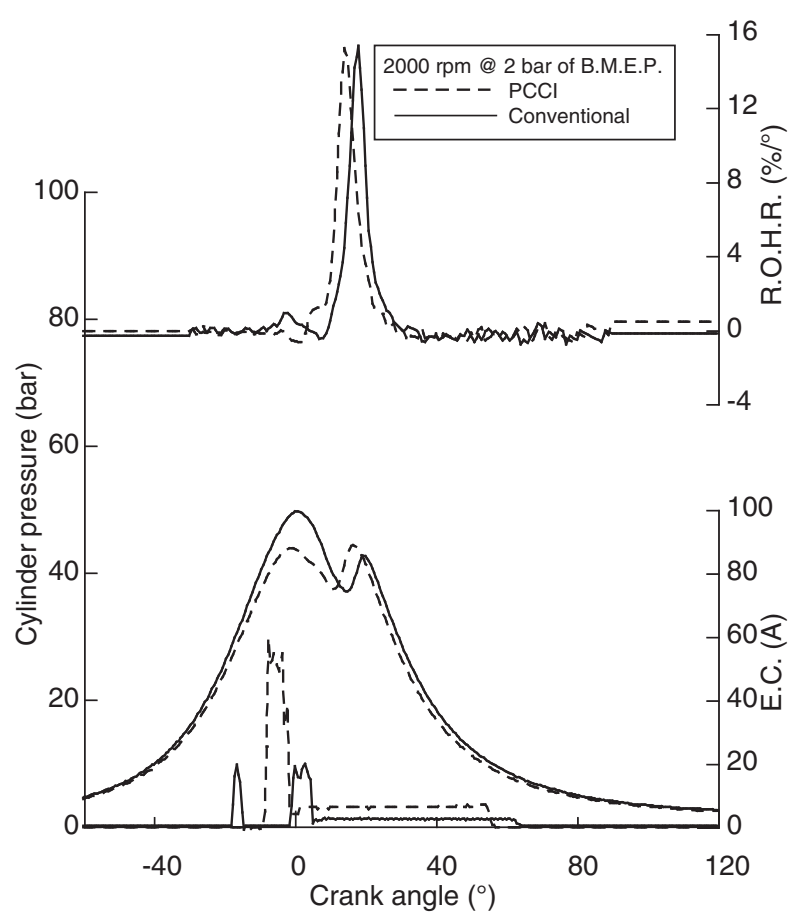

Figure 1

Comparison of cylinder pressure, energizing current (E.C.) and heat release rate curves between conventional and PCCI operation mode. Engine point: 2000 rpm @ 2 bar of BMEP.

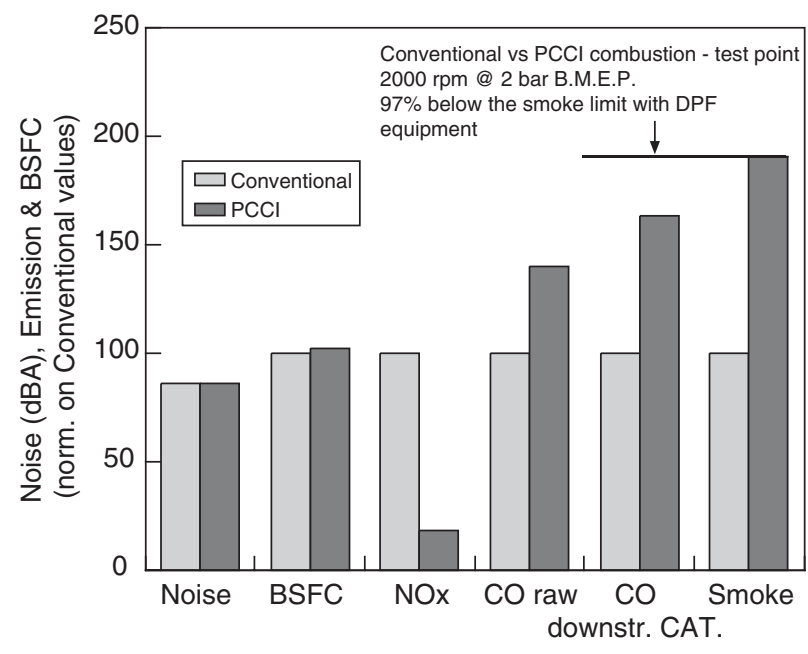

Figure 2

Comparison between conventional and PCCI operation mode in terms of engine performance and emissions. Engine point: 2000 rpm @ 2 bar of BMEP.

This result can be easily explained because of the lower flame temperature and the higher premixed charge fraction in the PCCI mode with respect to the Diesel mode, that producing in the PCCI mode an exhaust temperature value below the threshold catalyst light-off temperature and higher unburned compounds. 


\subsection{MK Combustion Concept}

As said above, the management of the PCCI concept is simple in the low load-low speed range of the NEDC map, but it becomes very difficult with the increasing of the engine load. In fact at high load, with the advancing of injection before the TDC and with the increment of the EGR level, the increment of combustion rate and the reduction of ignition delay time become uncontrollable.

To control the premixing level and the combustion rate at higher engine load the MK combustion concept is based on a single injection strategy with a retarded injection timing around TDC, taking advantage from the rapid drop of gas temperature during the expansion stroke. To this aim, in order to limit the consequent increase of fuel consumption due to the reduced combustion temperature and to the higher heat losses through cylinder wall, an adequate preparation of the premixed air-fuel charge is necessary. In the MK concept this objective is pursued, within the shortest ignition delay time, controlling adequately both the injection pressure and the swirl level.

The behavior of a MK combustion compared with the conventional Diesel one is reported in Figure 3. Looking at the two heat release rate curves it is evident the shift toward expansion stroke of the MK combustion with the penalty in fuel consumption. The injection timing was set in order to control the combustion noise below a limit of $80 \mathrm{bar} / \mathrm{ms}$.

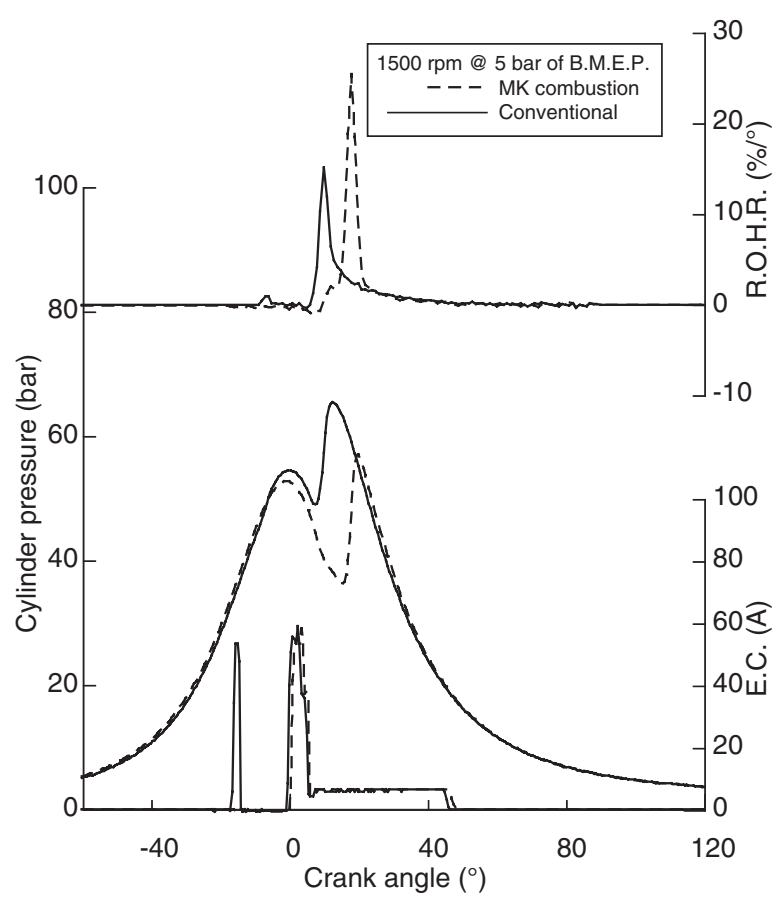

Figure 3

Comparison of cylinder pressure, energizing current (E.C.) and heat release rate curves between conventional and $\mathrm{MK}$ operation mode. Engine point: 1500 rpm @ 5 bar of BMEP.

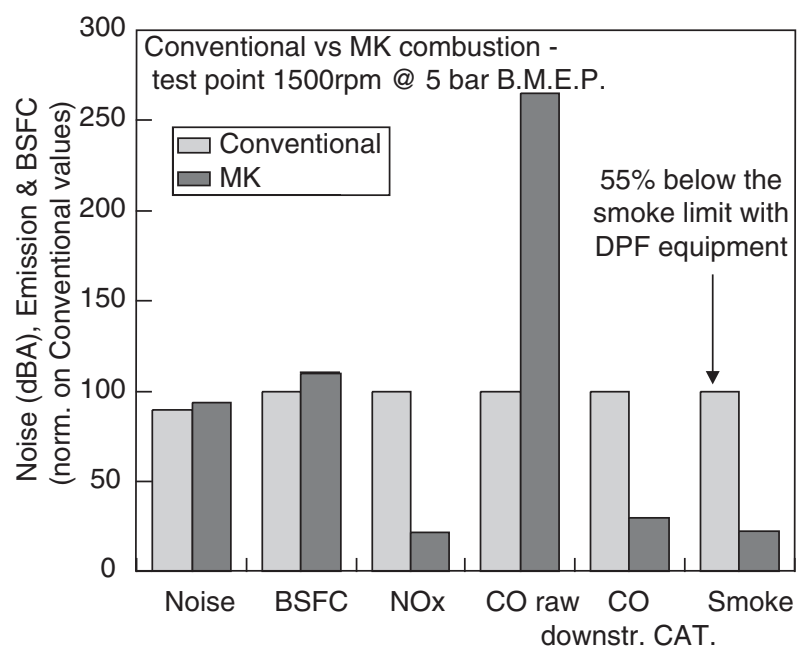

Figure 4

Comparison between conventional and MK operation mode in terms of engine performance and emissions. Engine point: 1500 rpm @ 5 bar of BMEP.

Controlling the maximum pressure rise with the retarded injection timing, as observable in Figure 3, the MBF50\% is placed so far from the TDC and notwithstanding the preparation of a premixed air-fuel charge, the oxidation of the unburned fractions stops before an almost complete combustion, as the high level of CO raw in Figure 4 demonstrates. However, the high exhaust temperature permits to keep a good catalysts efficiency, evidenced by the low CO emissions downstream the catalyst.

NOx and smoke, reported in Figure 4, are controlled by the premixed level and by the low temperature combustion. As evident in Figure 4 the increase in fuel consumption produced in MK conditions over $10 \%$ with respect to the EURO 4 standard values limits its application, for the engine employed in the tests, to a maximum load equivalent to 5 bar of BMEP in the speed range $1000 \mathrm{rpm}$ to $2500 \mathrm{rpm}$.

\section{PRACTICAL APPLICATION CONSTRAINTS OF THE LTC CONCEPTS}

\subsection{Cycle-to-Cycle and Cylinder-to-Cylinder Variability}

Different problems must be solved yet in order to obtain an "on road" combustion system NOx and soot free. Generally low combustion temperature systems (PCCI, MK, etc.) are characterized by similar problems as low maximum attainable engine load, high gaseous unburned emissions and difficult control of in-cylinder charge distribution and ignition timing, especially in transient conditions. The last issue is the main drawback occurring in the LTC application to real four-cylinder engines. 


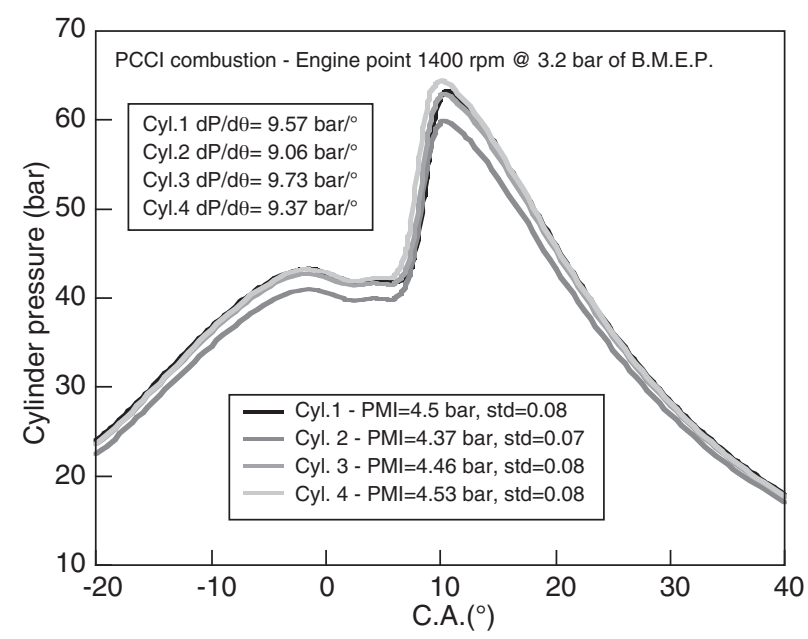

Figure 5

Cylinder pressure variation among the four cylinders under PCCI operation mode. Engine point: 1400 rpm @ 3.2 bar of BMEP.

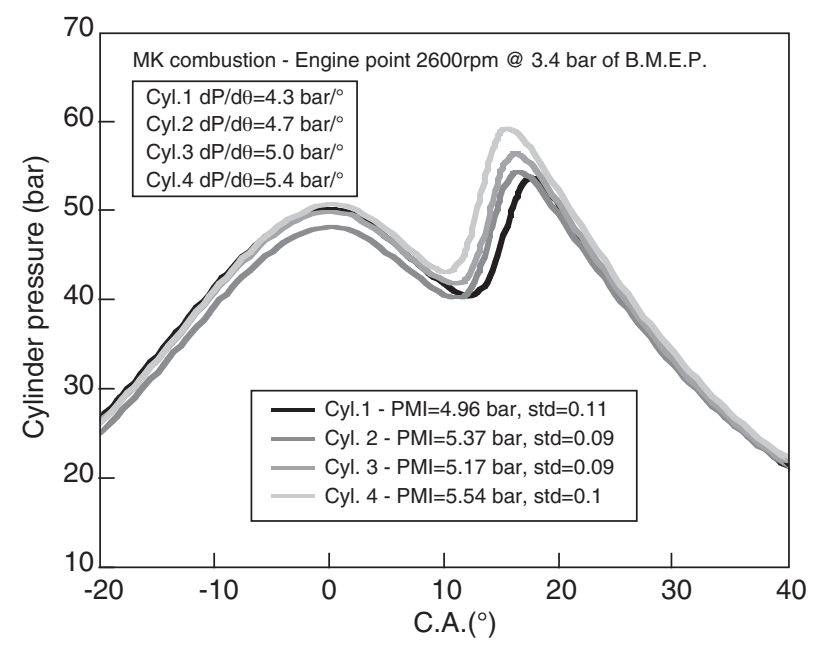

Figure 7

Cylinder pressure variation among the four cylinders under MK operation mode. Engine point: 2600 rpm @ 3.4 bar of BMEP.

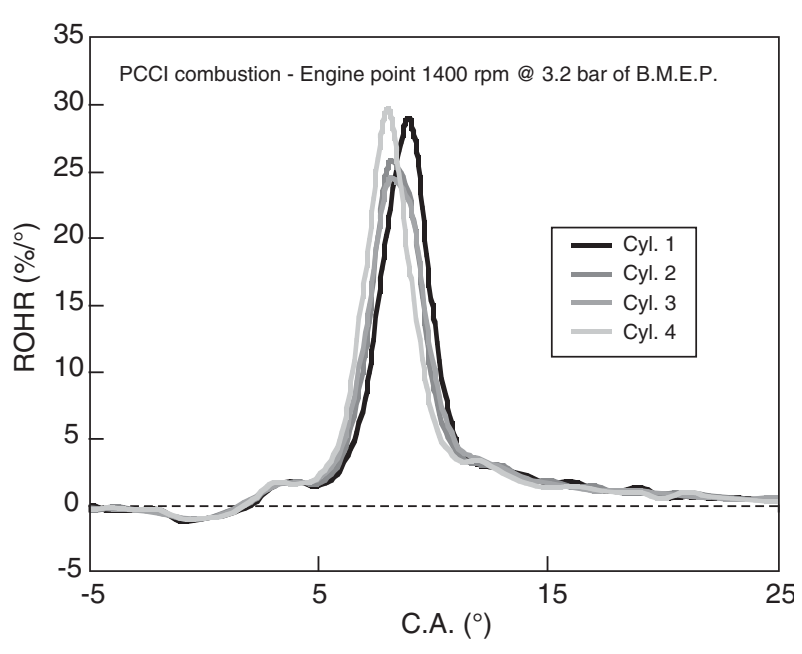

Figure 6

Heat release rate variation among the four cylinders under PCCI operation mode. Engine point: 1400 rpm @ 3.2 bar of BMEP.

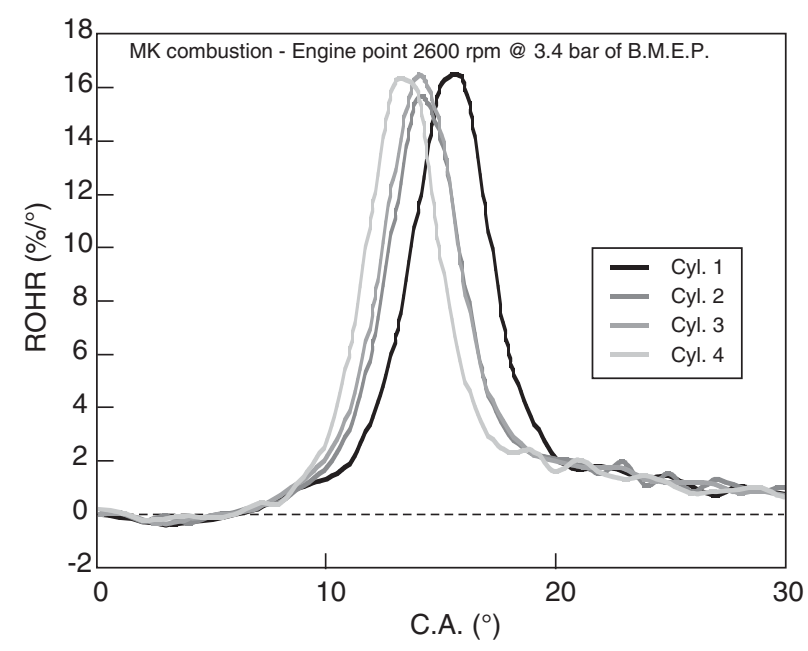

Figure 8

Heat release rate variation among the four under MK operation mode. Engine point: 2600 rpm @ 3.4 bar of BMEP.
In particular, if the control of a stable combustion in steady-state conditions is easy enough for a single cylinder, in a multi-cylinder engine, problems derive from the different feeding of each cylinder and the different characteristic between cylinders (compression ratio, cooling, geometry, etc.). In order to observe these differences, all cylinders of the multi-cylinder were instrumented with a pressure piezoquartz transducer.

In Figures 5-8, the comparison of cylinder pressure and heat release rate for all cylinders in two different test points are shown. Figures 5 and 6 refer to a PCCI combustion, while Figures 7 and 8 regard to MK combustion mode. The particular test conditions are calibration points of an engine control map with LTC combustion able to approach EURO6 limits.

Looking at the figures, it is easy observable that the use of LTC concepts offers problem of combustion balancement among the cylinders. This effect is typical of high EGR operation in multi-cylinder engines, and generally increases with engine load and speed with the LTC combustion mode that shifts from the PCCI mode toward the MK mode. In conventional Diesel operation mode the differences are smaller, as Figures 9 and 10 evidence. In this case, as well known, the presence of pilot combustion has a strong effect on the control of the ignition delay. 
In Figures 5-8, the standard deviation "std" in the PMI calculation is reported for each cylinder in PCCI and MK combustion respectively. Under LTC conditions, with respect to the conventional Diesel mode, the cycle-by-cycle variability is increased by the more significant ignition delay variation. This effect is more evident moving from PCCI to MK combustion mode. In this last case, in fact, the cycle-by-cycle variability of ignition delay derives from the decreasing of incylinder temperature and pressure in the first expansion stroke that increases the autoignition process instability.

Relatively to the cylinder-by-cylinder variability it can be noticed that the classical problems deriving from the different feeding and different characteristic among cylinders are emphasized in LTC conditions as illustrated both in terms of in-cylinder pressure and rate of heat release.

The first characteristic to be taken into account consists in the unavoidable constructive difference in the geometrical compression ratio of each cylinder. This light difference in geometrical compression ratio values for each cylinder produces significant variation on the compression curves in terms of pressure and temperature at TDC (Fig. 11) and therefore on ignition delay time. This effect is present in the case of PCCI combustion (Fig. 5) and is more important in MK conditions (Fig. 7).

Differences in cylinder feeding both in terms of temperature and composition of the intake charge have a great

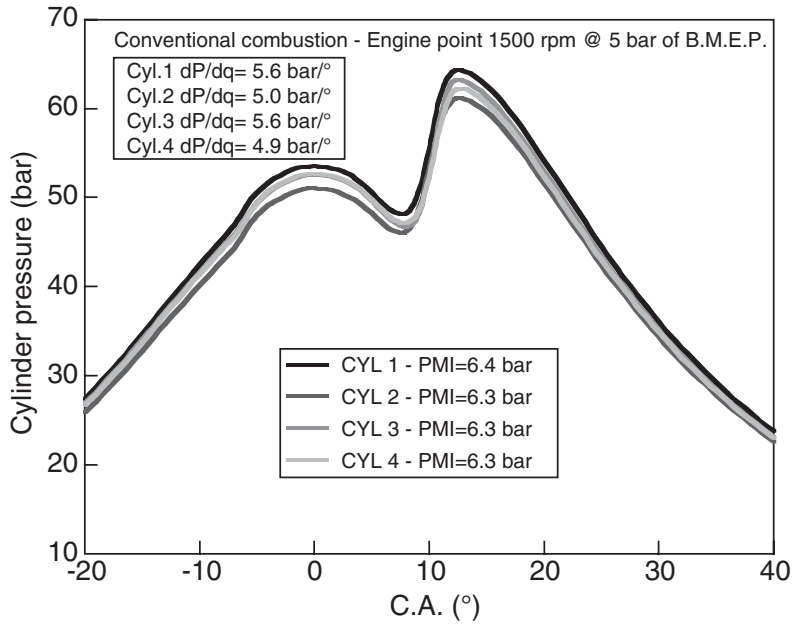

Figure 9

Cylinder pressure variation among the four under conventional combustion. Engine point: 1500 rpm @ 5 bar of BMEP.

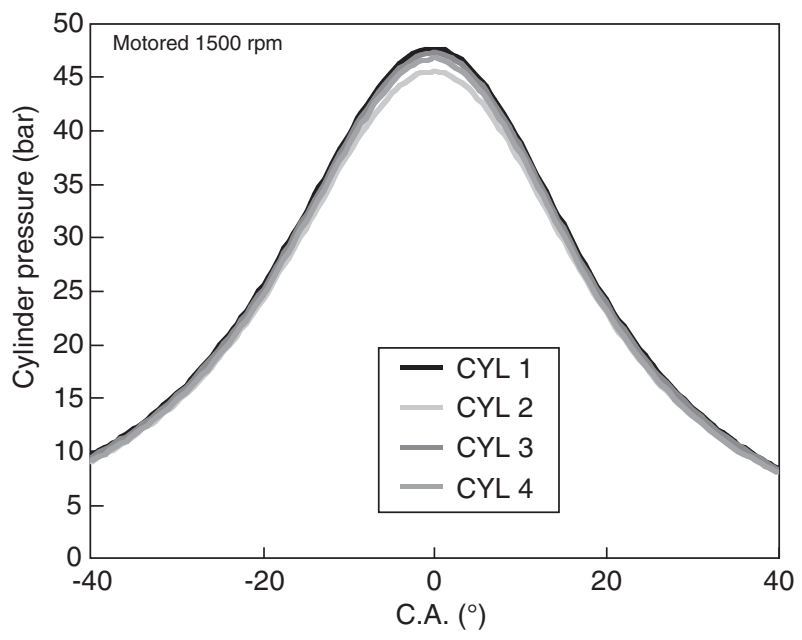

Figure 11

Cylinder to cylinder pressure variation in motored conditions at $1500 \mathrm{rpm}$.

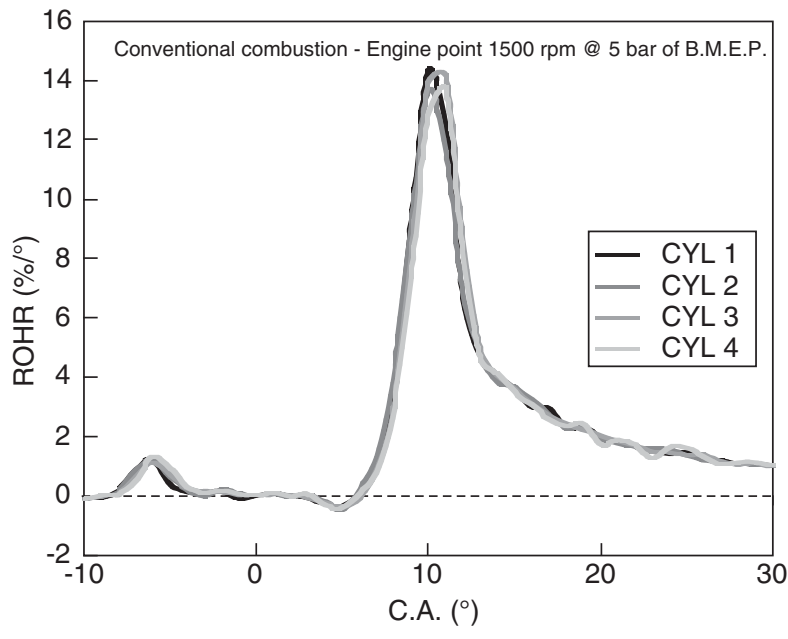

Figure 10

Heat release rate variation among the four under conventional combustion. Engine point: 1500 rpm @ 5 bar of BMEP.

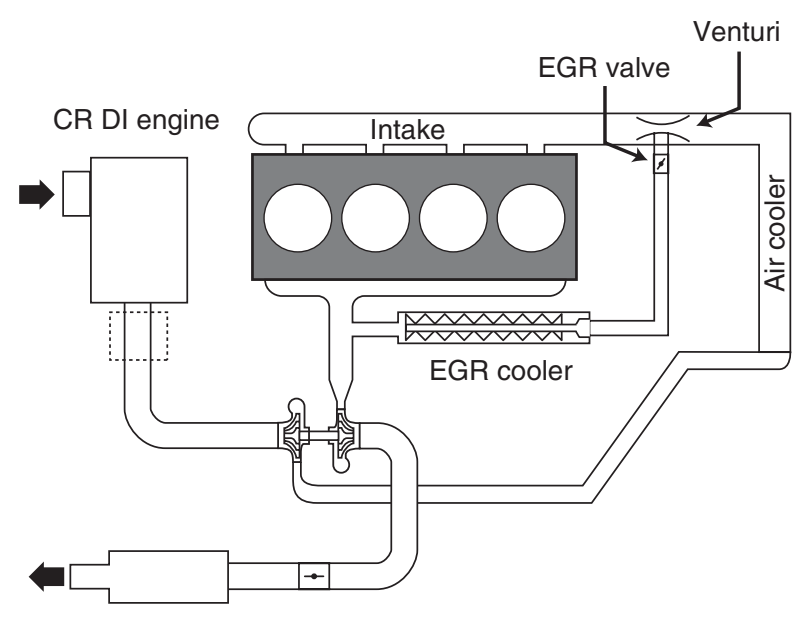

Figure 12

Intake and exhaust systems layout of the tested engine. 


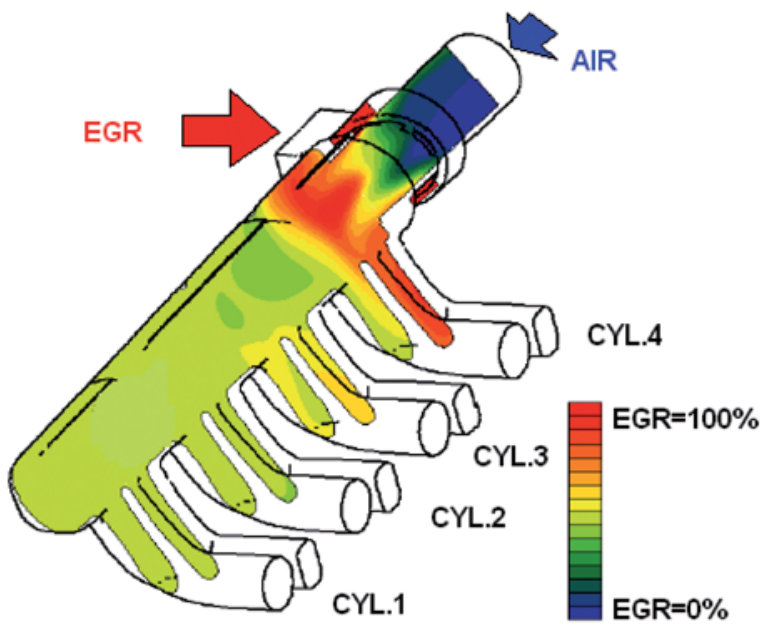

Figure 13

Typical EGR distribution inside intake plenum). The Figures are courtesy supplied by Centro Ricerche Fiat.

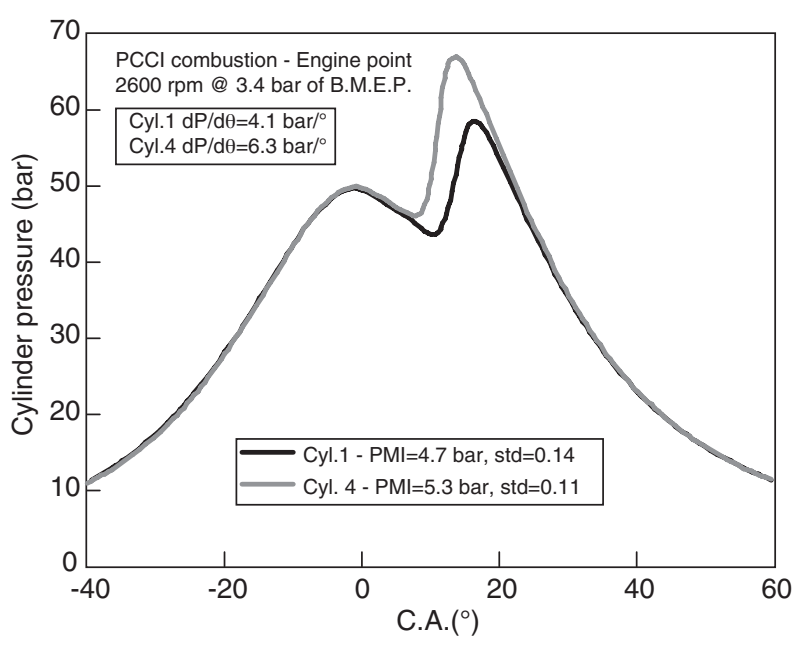

Figure 14

Cylinder pressure variation between cylinder No. 1 and No. 4 in PCCI operation mode. Engine point: 2600 rpm @ 3.4 bar of BMEP. importance relatively to the cylinder-by-cylinder variation. Due to the different geometrical position of different cylinders with respect to the intake manifold, the intake charge of air and EGR gases is affected by problems deriving from a non-uniform distribution of exhaust gases concentrations. This effect is observable in Figures 12 and 13, where the typical geometry of intake and exhaust systems layout of most of production four cylinder engines and the fresh air and exhaust gases distribution in the intake plenum are reported respectively, for the EGR conditions characteristics of LTC combustions.

The non-uniform EGR distribution is obviously associated with a non-uniform distribution of intake charge temperature so producing the appreciable differences in pressure curves for the farthest cylinders (number 4 and 1 ). Therefore and as evidenced in Figures 5 and 6, even considering the little differences in motored conditions, cylinders 4 and 1 show sensibly different ignition delay times. This demonstrated that the effect of a non-uniform intake charge temperature distribution is relatively more important than the correspondent nonuniform exhaust gases concentration distribution causing a favored autoignition process for cylinder 4 . This phenomenon could become critical in particular engine running conditions producing knocking for one cylinder and misfire and/or instability combustion for other cylinders, as evidenced in Figures 14 and 15 for cylinders 1 and 4 .

All these aspects contribute to explain the increase of combustion variability cylinder-to-cylinder in LTC mode with respect to the conventional Diesel mode giving sensible differences in terms of IMEP, noise and pollutant emissions for each cylinder. The exposed issues must be carefully considered relatively to the control of the engine if for this last average parameters among the cylinders are taken into account.

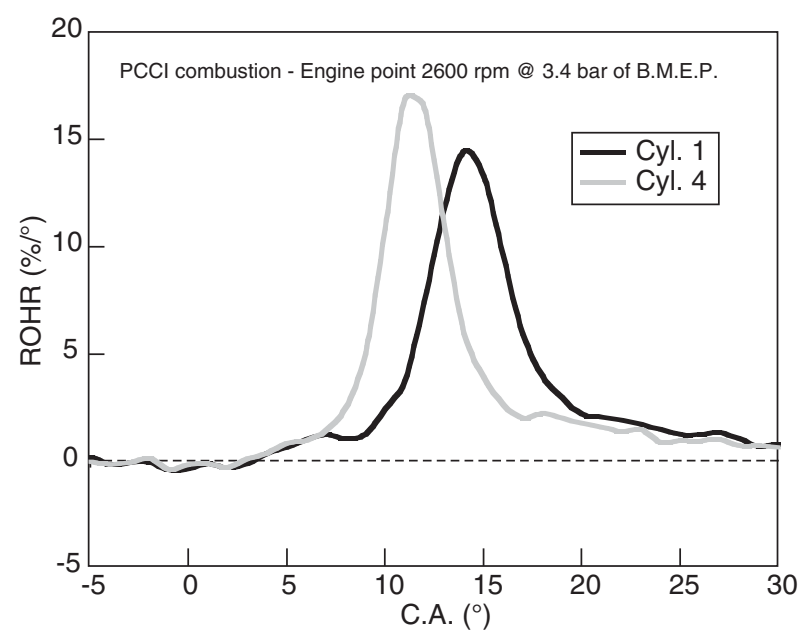

Figure 15

Heat release rate variation between cylinder No. 1 and No. 4 in PCCI operation mode. Engine point: 2600 rpm @ 3.4 bar of BMEP.

In fact, while with a high cylinder-to-cylinder variability, the average BMEP among the cylinders well represents the engine torque at the crankshaft, on the other hand it is not possible to assume a similar average value for noise and pollutant emissions as representative of engine performance. Adequate strategies of engine control will be necessary in order to minimize the lack of balance among the cylinders if this aim is not possible via new engine hardware design.

If the closed-loop engine control based on the measurement of in-cylinder pressure should be a solution for the 
practical application of LTC combustions the above results demonstrate that this control must be implemented for each cylinder separately, differently from some recent literature results where the engine control was based only on the acquisition of pressure signal for the first cylinder [7].

\subsection{Load and Pressure Rise Control in Transient Conditions}

Another problem regarding the use of a dual operation engine map (LTC and conventional modes) is the load and pressure rise control during the transition from LTC and conventional Diesel operation mode and vice versa. This situation is typical during the rapid car acceleration and deceleration.

Some simple tests were performed switching (with an on/off mode) the engine parameter set between normal and LTC conditions at a fixed engine test point, without using any transient control strategy but only evaluating the intermediate engine conditions deriving from the on/off switches. The engine test point was at low speed and load conditions (1500 rpm @ 2 bar P.M.E.) and so the LTC combustion mode adopted was the PCCI mode.

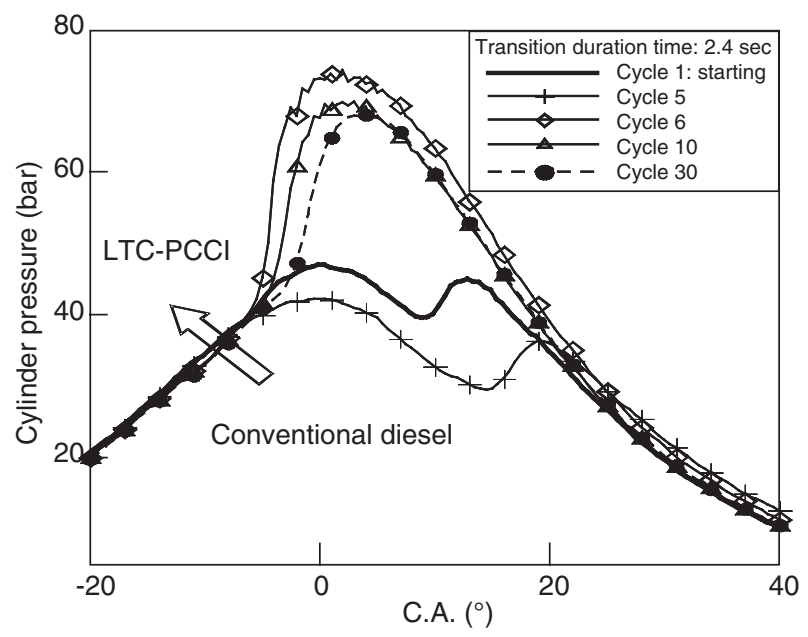

Figure 16

Cylinder pressure curve evolution for the transition from conventional Diesel combustion to LTC operation mode Engine conditions: 1500 rpm @ 2 bar of BMEP.

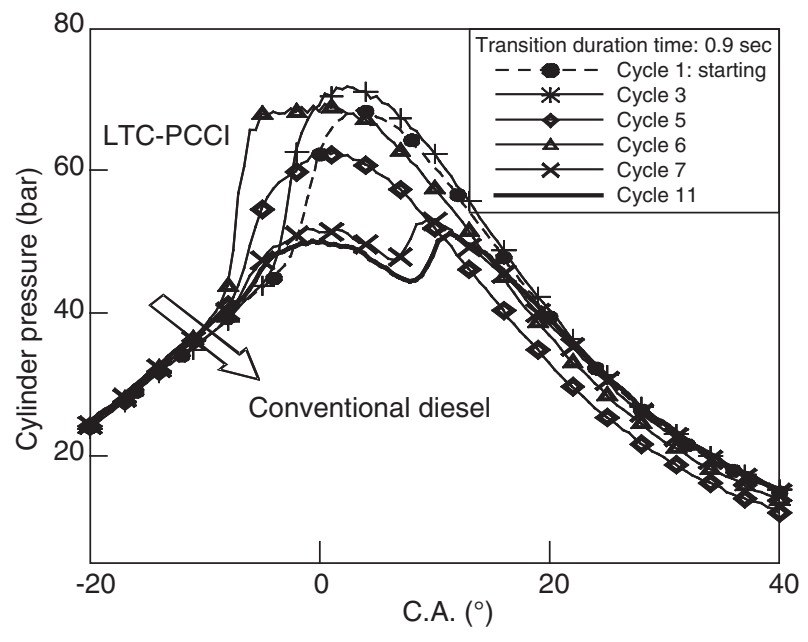

Figure 18

Cylinder pressure curve evolution for the transition from LTC combustion to conventional Diesel operation mode. Engine conditions: 1500 rpm @ 2 bar of BMEP.

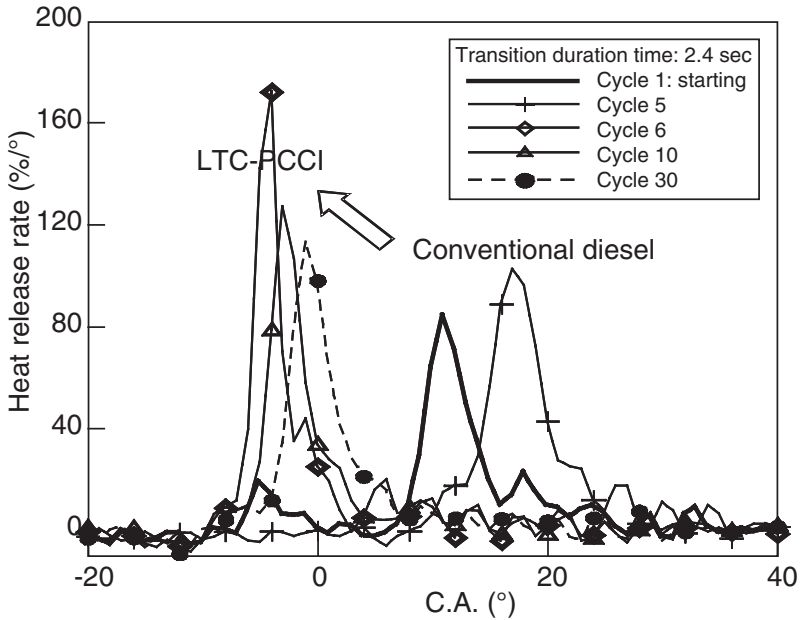

Figure 17

Heat release rate curve evolution for the transition from conventional Diesel combustion to LTC operation mode Engine conditions: 1500 rpm @ 2 bar of BMEP.

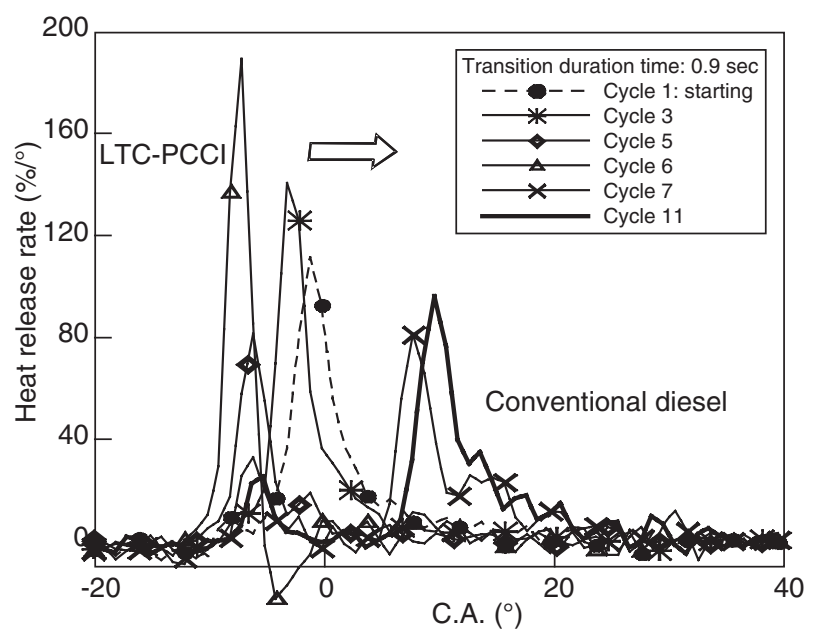

Figure 19

Heat release rate curve evolution for the transition from LTC combustion to conventional Diesel operation mode. Engine conditions: 1500 rpm @ 2 bar of BMEP. 
Indicated pressure traces were acquired and Figures 16, 17,18 and 19 report the pressure curve and the heat release rate switching the engine from conventional to LTC and vice versa, respectively.

Looking at the figures it is notable that the transition follows different ways if the engine shifts from conventional to PCCI or vice versa. Moreover, also the transition time necessary to reach a new steady state condition is different. Moving from Diesel conditions to PCCI, a time of about 2.4 seconds is needed, while from PCCI to Diesel ones, only 0.9 seconds are required. This is due to the adjustment of EGR circuit to the new conditions, that it is slower moving toward high EGR rate with respect to the opposite direction. This effect obviously derives from the engine architecture that presents a recirculated gases circuit longer with respect to the fresh air circuit.

The transition effect on engine performance can be also analyzed from Figures 20 and 21 where the evolution of IMEP and maximum pressure rise are plotted respectively. In Figures 20 and 21 only the behaviour of the first cylinder is reported, but taking into account the analysis on cylinder-tocylinder deviation, it is easy to think that more critical conditions than the first cylinder's ones can occur in the other cylinders as, for example, high knocking or misfiring.

The passage from Diesel to PCCI does not present particular problems in terms of IMEP and is coupled with a slightly IMEP increase. As regard to the maximum cylinder pressure rise, directly related to the combustion noise, the diagram of Figure 21 indicates that some constraints are evident relatively to the transition from Diesel to LTC mode, showing a peak in pressure rise before the transition is accomplished. Also this result depends on the slowness adjustment of the EGR circuit control. In fact, before this adjustment was accomplished the injection strategy passes instantaneously from a pilot-main strategy to a single advanced injection responsible of high combustion noise until the EGR rate rises up to its final value. In Figures 16 and 17 these transition cycles (cycles 6 and 10) are also responsible of high NOx emissions.

In the same figures it is shown that the opposite passage from LTC to Diesel presents a critical transition producing an engine torque drop for a few engine cycles. In Figure 20 an evident minimum IMEP peak and in Figure 21 a little pressure gradient peak are notable before the conventional Diesel conditions are reached. This effect can be explained considering the operation strategy of the ECU relatively to the variation of injection strategy. In this case, to attain Diesel conditions the ECU works introducing firstly the pilot injection and then retarding the main injection. This temporal sequence, as activated by the ECU, causes higher compression work and as a consequence lower indicated work output of some engine cycles up to the final injection strategy (pilot with main retarded) is achieved. Figure 18 shows few engine cycles (cycles 3, 5 and 6) responsible of the torque drop and the light pressure gradient peak.

On the base of previous considerations, the control of EGR rate during the transition between different operation modes (PCCI-MK-Diesel) appears one of the main issues in the practical application of LTC combustion to Diesel engines. This is due to the fact that the response rate of EGR circuit is slower than the injection system's one and moreover the time needed to reach the desired intake conditions varies if the EGR valve is being opening or closing. To this reason, during transition from LTC to conventional Diesel mode, the engine response

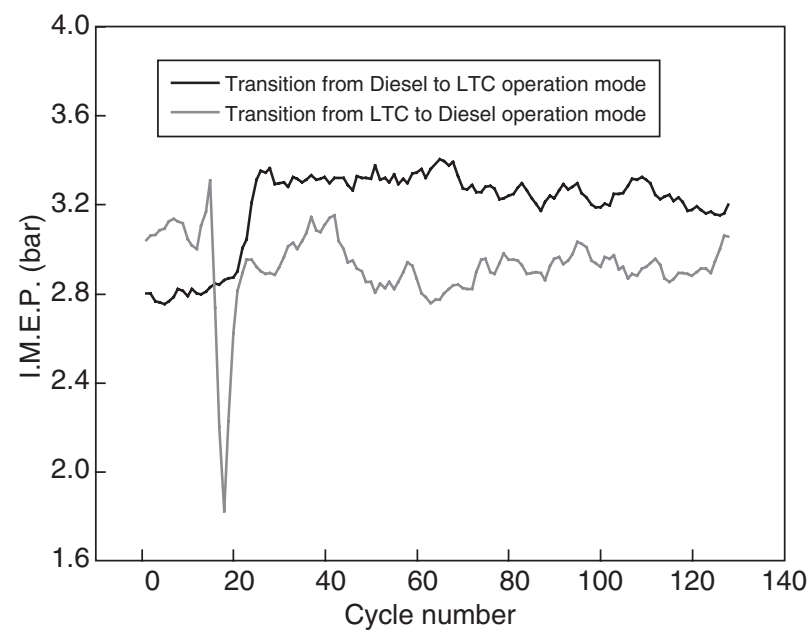

Figure 20

Indicated Mean Effective Pressure versus engine cycle during transition from normal to LTC operation mode and vice versa. Engine condition: 1500 rpm @ 2 bar of BMEP.

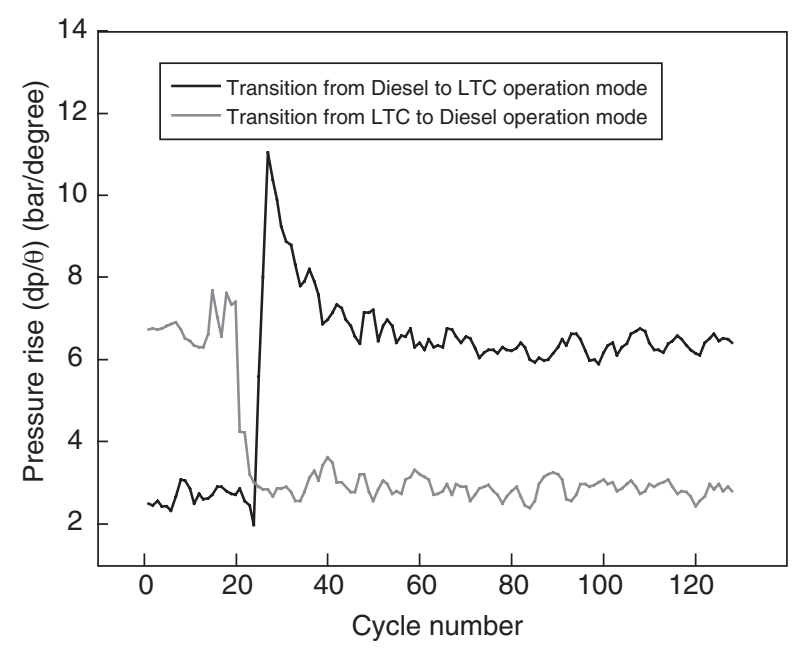

Figure 21

Maximum Pressure rise versus engine cycle during transition from normal to LTC operation mode and vice versa. Engine condition: 1500 rpm @ 2 bar of BMEP. 
to the EGR valve closing is sufficiently fast and, to avoid torque drop and knocking (see Fig. 20 in terms of I.M.E.P. behaviour and Fig. 21 in terms of pressure rise evolution), an adequate control of injection parameters (for example a progressive retarding of injection timing and the injection pressure reduction) appears easily realizable.

Relatively to emissions the transition from Diesel to LTC (see Fig. 16 in terms of cylinder pressure evolution and Fig. 17 in terms of heat release rate) appears more and more difficult. In fact, due to the slowness adjustment of intake duct conditions during EGR valve opening, the simple switch from Diesel to LTC parameters could pass very easily through high smoke conditions so engine control appears much more critical. In fact, during the increase of EGR and before the final highly premixed conditions will be attained, Figure 17 shows that some cycles (up to cycle 5) are characterized by a diffusive combustion under relatively high EGR rate and so they are responsible of high smoke emissions.

High soot production during transition from Diesel to LTC can be also explained considering the well known soot yield curve versus flame temperature. In fact, under pyrolysis conditions, with the reduction of flame temperature the tendency of soot formation crosses its peak value before the left side of the yield curve is reached (for more details see [8]). As example to confirm previous considerations, assuming to simulate the transition from Diesel to LTC as a sequence of quasi-steady state test points, Figure 22 shows the soot-NOx trade-off for some of them.

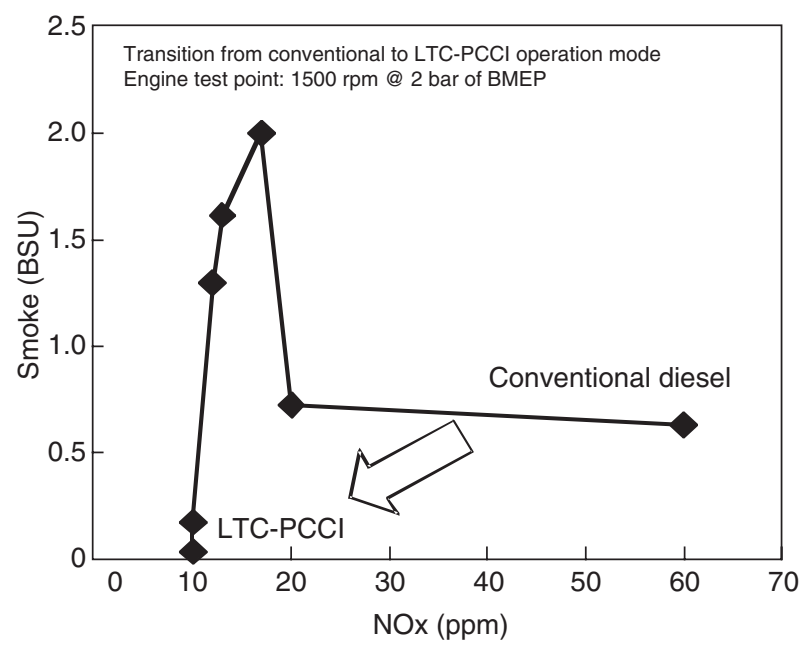

Figure 22

Simulation of trade-off NOx-smoke transition from conventional Diesel to LTC (PCCI). Engine conditions: 1500 rpm @ 2 bar of BMEP.
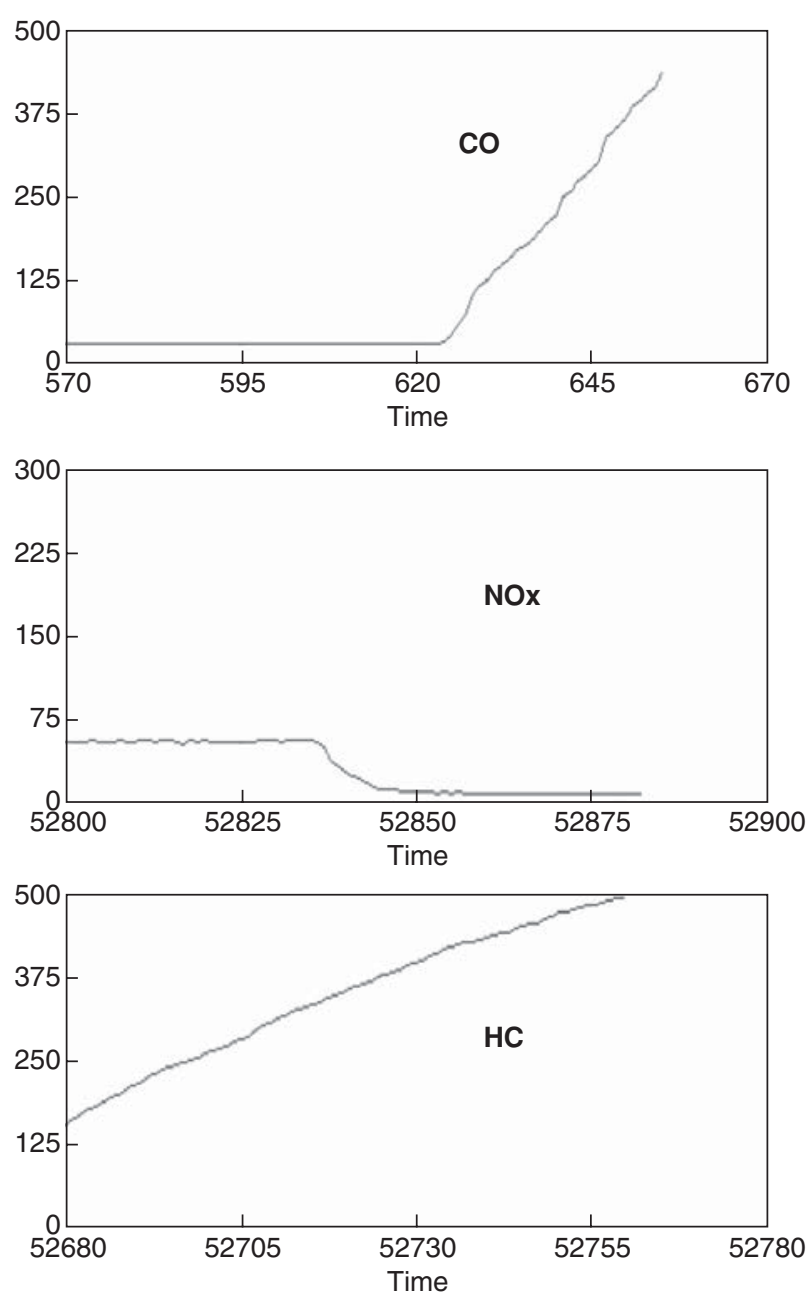

Figure 23

Gaseous emission during transition from conventional Diesel to LTC (PCCI) combustion. Engine conditions: 1500 rpm @ 2 bar of BMEP. Emission values are expressed in ppm while the $\mathrm{x}$ scale is in second.

Figure 23 reports the evolution of gaseous emissions during transition from Diesel to LTC combustion. The emission test bench is not synchronyzed with the switching of engine conditions, therefore it isn't possible to identify the exact start of the transition period. Anyway Figure 23 shows stationary initial conditions before the switch and final LTC conditions. As regard to unburned pollutant emissions, as well known LTC combustions present higher $\mathrm{HC}$ and $\mathrm{CO}$ values at raw exhaust.

In Figure 23 it is possible to note that, for $\mathrm{CO}$ and NOx a well defined start time of switching from Diesel to LTC is appreciable, while $\mathrm{HC}$ concentrations show a progressive increase. The difference between $\mathrm{HC}$ and $\mathrm{CO}$ behaviour demonstrates that mechanisms controlling their emissions 

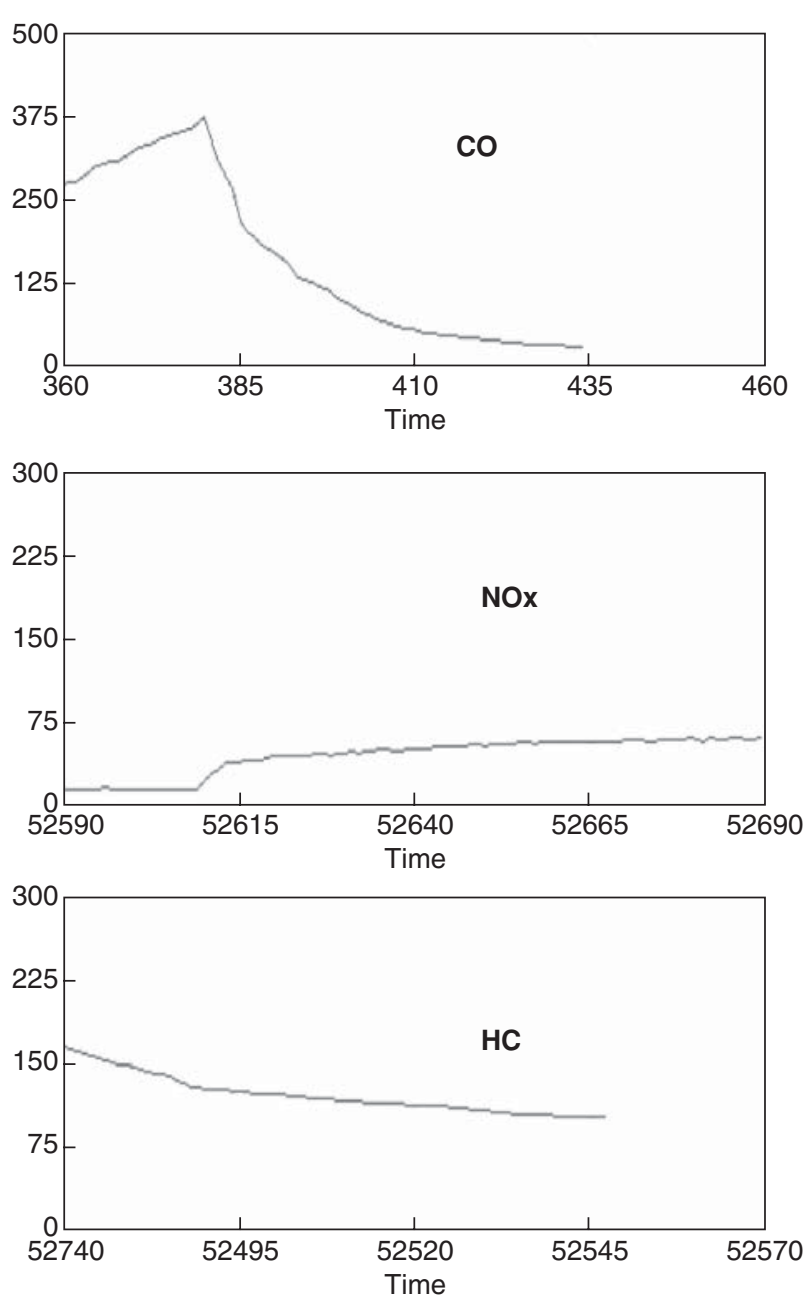

Figure 24

Gaseous emission during transition from LTC (PCCI) combustion to conventional Diesel. Engine conditions: 1500 rpm @ 2 bar of BMEP. Emission values are expressed in ppm while the $\mathrm{x}$ scale is in second.

aren't exactly the same. The evolution of NOx shows directly a good reduction of NOx when LTC combustion is attained but, due to the not so fast emission acquisition system, it doesn't show high peak of NOx value deriving from some transition cycles (cycles 6 and 10), as mentioned above. Figure 24 reports the inverse transition from LTC to Diesel combustion with a quite reverse behavior with respect Figure 23.

High unburned emissions emitted in LTC combustion mode aren't a critical aspect in medium-high load engine conditions coupled with a satisfying efficiency of oxidation catalyst, while they must be carefully considered at low load points because of the oxidation catalyst temperature under its light-off value, as observable in Figure 2. This means that, at extremely low load conditions, the use of conventional combustion will be still needed if a further effort on both combustion system and aftertreatment layout improvement isn't accomplished. In the first case the engine map would be more fragmented and more complexity would derive from an additional control area in the whole engine operating map.

\section{CONCLUSION}

The present paper describes some critical aspects deriving from the use of one of the LTC management philosophies, today under development for application to Diesel engines.

In particular the analysis was addressed to the cylinder-tocylinder variation under LTC combustion and to problems deriving from the transition control between conventional and LTC modes and vice versa. Results demonstrate that further work is needed for practical application of LTC concepts to Diesel production engines. Moreover some methodologies as closed-loop control and VVA system seem essential in order to obtain acceptable control of transient conditions and intake-exhaust gas flow characteristics.

The aspects here considered are only some of the problems of control in the low temperature combustion systems but the current advanced engine technology seems quite ready to overcome them.

\section{ACKNOWLEDGEMENTS}

Authors would like to tank Dr. M.G. Lisbona and Dr. M. Tonetti of Fiat Research Center (C.R.F.) for their contribution in the analysis of engine behavior under LTC combustion.

\section{REFERENCES}

1 Duret, P. (2001) A new generation of engine combustion processes for the future - Keynote addresses, Proceedings of IFP International congress: A new generation of engine combustion processes for the future, Technic eds., RueilMalmaison, France, pp. 1-7.

2 Gatellier, B., Walter, B. and Miche, M. (2001) New Diesel Combustion Process to Achieve Near Zero NOx and Particulate Emissions, Proceedings of IFP International congress: A new generation of engine combustion processes for the future, Rueil-Malmaison, France, pp. 43-54.

3 Yanagihara, H. et al. (1996) A Simultaneous reduction of NOx and Soot in Diesel Engines under a New Combustion System (uniform bulky combustion system UNIBUS). 17th International Vienna Motor Symposium.

4 Sasaki, S., Ito, T. and Iguchi, S. (2000) Smoke-less Rich Combustion by Low Temperature Oxidation in Diesel Engine. 9th Aachen Colloquium Automobile and Engine Technology 2000 , p. 767. 
5 Shimazaki, N., Akagawa, H. and Tsujimura, K. (1999) An Experimental study of Premixed Lean Diesel combustion. SAE Paper 1999-01-0181.

6 Kimura, S., Aoki, O., Kitahara, Y. and Aiyoshizawa, E. (2001) Ultra-Clean Combustion Technology Combining a LowTemperature and Premixed Combustion Concept for Meeting Future Emission Standards. SAE Paper 2001-01-0200.
7 Bürgler, L., Glensvig, M., Neunteufl, K. and Weißbäck, M. (2005) Vehicle Application with Alternative Diesel Combustion, MTZ 112005.

8 Beatrice C., Bertoli C. and Di Lorenzo A. (2006) The evolution of the Diesel combustion system toward the near zero emission goal. Int. J. Vehicle Design, 41, 1/2/3/4, 3-17.

Final manuscript received in May 2007 